\title{
Regulação de produtos saneantes no Brasil: registro, notificação, embalagem e rotulagem
}

\author{
Regulation of sanitizing products in Brazil: registration, \\ notification, packaging and labeling
}

Recebido em: 25/08/2016

Aceito em: $12 / 102016$
Ana Caroline Gabriel GONÇALVES ${ }^{1}$; Samara Lima ALMEIDA ${ }^{2}$

${ }^{1}$ Departamento de Farmácia. Faculdade de Ciências da Saúde Universidade de Brasilia., Campus Universitário Darcy Ribeiro, Asa Norte, CEP 70910-900, Brasilia, DF, Brasil. ${ }^{2}$ Secretaria de Saúde do Distrito Federal, Setor Bancário Norte, Quadra 02, bloco P, lote 4, CEP 70040-020, Brasília, DF, Brasil.E-mail: anacarolinegg@hotmail.com

\section{ABSTRACT}

Sanitizing products with several purposes of use are becoming increasingly popular in the Brazilian market. Consumers are looking for products that keep their homes and environments clean and free of pests. The increasing use of sanitizing products has brought along with it the great responsibility of their regularization. Brazilian Health Surveillance Agency is responsible for approving sanitizing products and post-marketing monitoring to ensure their quality and safety. In this paper, it was carried out a review of legislations that approach registration, notification, packaging and labeling of sanitizing products. These legislations were created with the aim of guiding producing companies, as well as users about the update of relevant information that must appear on each product label, as well as the key features of the packages. This information is necessary to help consumers to properly use products, identify their legitimacy as well as their quality and prevent accidents.

Keywords: sanitizer; registration, notification; labeling; packaging

\section{RESUMO}

Produtos saneantes com diversas finalidades de uso são cada vez mais populares no mercado brasileiro. Os consumidores buscam produtos que mantenham suas casas e ambientes limpos e livres de pragas. A crescente utilização de saneantes trouxe consigo uma maior responsabilidade de sua regularização. A Agência Nacional de Vigilância Sanitária é responsável pela aprovação e fiscalização pós mercado destes produtos de forma a garantir qualidade e segurança. Neste trabalho, foi realizada uma revisão de legislações que abordam registro, notificação, embalagem e rotulagem de saneantes. Estas legislações foram criadas com o intuito de orientar empresas produtoras, assim como os usuários quanto à atualização das informações importantes que devem constar no rótulo de cada produto, assim como as principais características das embalagens. Essas informações são importantes para ajudar os consumidores a utilizar produtos de forma apropriada, identificar sua legitimidade bem como sua qualidade e prevenir acidentes.

Palavras-chave: saneante; registro; notificação; rotulagem; embalagem

\section{INTRODUÇÃO}

Saneante pode ser definido como qualquer substância ou preparação destinada a desinfecção, higienização ou desinfestação de ambientes e objetos ou utilizada para o tratamento de água. Estes podem ser utilizados em ambientes domiciliares, hospitalares, públicos ou coletivos $(1,2)$. E as substâncias saneantes podem ser classificadas, de acordo com sua finalidade de utilização, nos seguintes grupos: saneantes desinfestantes, que são produtos destinados a eliminação de pragas, tais como raticidas e inseticidas; saneantes com ação antimicrobiana, como por exemplo desinfetantes, desodorizantes, utilizados para destruir ou impedir o desenvolvimento 
de microrganismos em diversos ambientes e produtos utilizados para limpeza $(3,4)$.

Produtos saneantes são utilizados no Brasil nos mais diversos meios. Em Hospitais, fica clara a importância da limpeza e desinfecção de ambientes e equipamentos com o objetivo de proteger a saúde de pacientes e profissionais (5). No ambiente domiciliar é comum utilizar saneantes para manter os ambientes limpos, livres de contaminação por microrganismos e pragas (6).

Campanhas publicitárias buscam chamar a atenção dos consumidores, ressaltando o brilho e o odor advindo do uso de saneantes e sempre exaltando a importância de eliminar microrganismos e pragas que trariam riscos a saúde humana (7).

Devido ao crescente consumo de produtos saneantes, a importância da Vigilância Sanitária no controle destes produtos é essencial. Existem saneantes clandestinos, que não receberam aprovação da Agência Nacional de Vigilância Sanitária (Anvisa) antes de serem comercializados. Estes produtos não passaram por testes que garantam sua eficácia e segurança. Na maioria das vezes não possuem a formulação correta para produzir o efeito desejado e podem gerar danos a saúde. Saneantes clandestinos geralmente possuem cores chamativas, cheiros atrativos e preços reduzidos. Uma das formas de identificar a procedência do produto é analisando o rótulo, que deve possuir a indicação de uso e dados da empresa fabricante (2).

Apesar dos benefícios advindos da utilização de produtos saneantes, os produtos químicos utilizados em sua composição podem causar efeitos tóxicos à saúde (6). Intoxicação é uma das maiores causas de mortalidade e morbidade em crianças, sendo que em muitos casos estes produtos ficam armazenados em locais que de fácil acesso nas casas (8). Vítimas de intoxicações por saneantes procuram muitas vezes a ajuda em Centros de Controle de Intoxicação (CCIs). Estes são responsáveis por prestar auxílio a pessoa intoxicada e registrar dados sobre estas intoxicações, tais como idade, sexo, nome do produto que casou a intoxicação e os eventos que se sucedem após o atendimento (9).

A Anvisa é o órgão responsável pela promoção e proteção da saúde, realizando controle sanitário da produção e comércio de saneantes no Brasil. É responsável pelo registro e notificação de produtos saneantes, assim como pela uniformização das informações que devem conter em seus rótulos e delimitação de regras para recipientes que os contenham. Um de seus objetivos é garantir a qualidade e segurança do produto antes e após sua comercialização, de forma a reduzir ao máximo os efeitos nocivos à saúde da população $(2,10)$.

Empresas que desejem fabricar produtos saneantes no Brasil, devem requerer uma Autorização de Funcionamento (AFE) junto à Anvisa, em que conste as atividades a serem desenvolvidas. Após a obtenção da AFE, estas devem solicitar licenciamento no órgão de vigilância sanitária local (Estados, Municípios ou Distrito Federal), que autoriza o funcionamento ou a operação para cada estabelecimento $(1,11)$. Para a utilização de alguns produtos específicos na fabricação de saneantes é necessária ainda uma autorização especial de outros órgãos, como corpo de bombeiros, órgão ambiental e exército (12).

Este trabalho apresenta a evolução de legislações para regularizar produtos saneantes junto à Anvisa, referentes a notificação, registro, rotulagem e embalagem. Estas são elaboradas com o objetivo de orientar empresas a fabricar produtos de qualidade e seguros em relação ao uso. As orientações são relevantes também aos usuários de saneantes, que devem estar cientes dos riscos envolvidos na manipulação e das vantagens de utilizar produtos verdadeiros.

\section{MATERIAIS E MÉTODOS}

Uma revisão da literatura foi realizada com o intuito de identificar as principais mudanças, ao longo dos anos, nas legislações acerca da notificação, registro, rotulagem e formas de embalagem de produtos saneantes. Para viabilizar a elaboração deste trabalho foram consultadas legislações referentes à regulação sanitária, disponíveis no sítio eletrônico da Anvisa e do Planalto da Presidência da República. Uma cartilha informativa sobre saneantes elaborada pela Anvisa e um guia sobre saneantes elaborado pelo Conselho Regional de Química foram consultados como fontes complementares.

Para a seleção de artigos científicos, foram pesquisadas fontes nacionais entre os anos de 2000 a 2016 de periódicos das bases de dados da Scielo. Apenas artigos na língua inglesa, espanhola ou portuguesa foram selecionados. Na busca foram utilizados os seguintes descritores: "saneantes" "análise química", "uso doméstico" e "saneantes clandestinos". Os descritores foram também combinados e após a busca foram aplicados os critérios de exclusão. Na primeira etapa foram analisados os títulos, em seguida os resumos e por último o texto do artigo. 


\section{RESULTADOS E DISCUSSÃO}

\section{Registro e notificação de saneantes.}

Registro é a inscrição, em livro específico, contendo o nome, o fabricante, a origem, a finalidade de uso e outras características do produto (1). Este deve conter nome, fabricante, origem, finalidade de uso e outras características do produto (3). Para regular o registro e notificação de saneantes no Brasil, foram adotadas classificações de risco. Risco é a probabilidade de que ocorra um evento adverso inesperado ou algum dano ao meio ambiente. Os principais critérios utilizados para a avaliação e gerenciamento de risco para saneantes são: finalidade e condições de uso, população alvo, frequência e duração da exposição, formas de apresentação e notificação de eventos adversos ou queixas anteriores (3).

A Portaria 57/1995, da Secretaria de Vigilância Sanitária do Ministério da Saúde, que dispõe sobre os procedimentos e requisitos técnicos para o registro de produtos saneantes, classificou, pela primeira vez, estes produtos em duas categorias de risco. Produtos de risco 2 seriam os que apresentassem atividade antimicrobianas, desinfetantes, os constituídos a base de microrganismos, os produtos que possuíssem alto poder oxidante ou redutor e $\mathrm{pH}$ menor que 2 ou maior que 13. Produtos de limpeza que não apresentassem características cáusticas ou corrosivas eram classificados como de risco 1, sendo que estes teoricamente apresentariam menor risco quando comparados aos produtos de risco 2. Segundo esta Portaria, todos os saneantes deveriam ser registrados junto a autoridade sanitária, inclusive os de risco 1 (13).

A Resolução 336/1999 da Anvisa modificou a classificação de risco, acrescentando a exigência de que o pH deveria ser medido em uma solução $1 \%$, sendo que produtos de risco 2 deveriam apresentar $\mathrm{pH}$ menor ou igual a 2 ou maior ou igual a 12 . A dose letal que mataria $50 \%$ de uma população exposta ao produto é conhecida como $\mathrm{DL}_{50}$. Assim, Foi estabelecida uma $\mathrm{DL}_{50}$ oral para ratos, que deveria ser superior a $2000 \mathrm{mg} / \mathrm{kg}$ de peso corpóreo, no caso de produtos líquidos, e inferior a $500 \mathrm{mg} / \mathrm{kg}$ de peso corpóreo, no caso de sólidos. Esta $\mathrm{DL}_{50}$ passou a ser válida para as duas classes de risco. De acordo com esta resolução, produtos considerados de risco 1 não precisariam de registro junto à Vigilância Sanitária, sendo necessária apenas a notificação, obtida após a entrega de dados sobre o produto e um termo de responsabilidade do fabricante. As empresas que possuíssem intenção de registrar novo produto saneante de risco 2, deveriam apresentar formulário de petição e dados sobre o produto à autoridade sanitária, contendo informações sobre a empresa conforme exigências constantes no corpo da resolução (14).

A Resolução da Diretoria Colegiada (RDC) 184/2001 da Anvisa revogou a Resolução 336/1999, alterando alguns requisitos para o registro de saneantes de risco 2 e notificação de saneantes de risco 1 . Produtos de risco 1 deveriam apresentar $\mathrm{pH}$ maior que 2 ou menor que 11,5; produtos de risco 2 deveriam apresentar $\mathrm{pH}$ menor ou igual a 2 ou maior que 11,5 , em solução $1 \%$ $\mathrm{p} / \mathrm{p}$. A temperatura na qual o $\mathrm{PH}$ da amostra deveria ser medida para a definição da classe de risco foi definida como $25^{\circ} \mathrm{C}$. A DL ${ }_{50}$ continuou a mesma definida pela Resolução anterior. Apresentou pela primeira vez a tabela com variações quantitativas aceitáveis, expressas em porcentagem, entre a quantidade de cada componente declarado pelo fabricante e a quantidade real da amostra analisada (15).

A RDC 42/2009 alterou o procedimento para notificação de saneantes, de risco 1 , implantando um novo procedimento eletrônico, denominado "Sistema de Peticionamento e Arrecadação Eletrônico", que pode ser acessado no sítio eletrônico da Anvisa. Este procedimento, ao ser finalizado, gera um protocolo contendo um Número Identificador do Produto, que deve constar no rótulo, de forma a permitir sua rastreabilidade. Esta Resolução também determina que as empresas devem notificar qualquer alteração, mantendo as informações do produto sempre atualizadas e protocoladas junto a Anvisa. Os documentos gerados após a finalização do procedimento eletrônico devem ser assinados pelo responsável técnico e pelo responsável legal da empresa, que deve mantê-los sobre sua posse, pois estes podem ser exigidos em futuras inspeções pela Vigilância Sanitária. O prazo de 12 meses foi definido para a atualização dos rótulos (16).

A RDC 59/2010, última em vigor sobre registro e notificação de saneantes, passou a exigir, das empresas interessadas no registro de produtos de risco 2, formulários emitidos pelo "Sistema de Peticionamento e Arrecadação Eletrônico", laudo dos estudos de estabilidade e do $\mathrm{pH}$, modelo do rótulo e da embalagem, dados sobre a empresa e cópia do alvará sanitário ou pedido de renovação da própria empresa e, quando existir, da empresa terceirizada. Produtos que contenham ácido fluorídrico, ácido nítrico, ácido sulfúrico ou seus sais que os liberem em condições de uso são classificados como de risco 2. $\mathrm{O} \mathrm{pH}$ dos produtos deve ser medido em sua forma pura, sendo que os valores continuam os mesmos da Resolução 
anterior, assim como a $\mathrm{DL}_{50}$ oral para ratos. Estudos de estabilidade passaram a ser exigidos para produtos de risco 1 com prazo de validade superior a 36 meses, devendo ser apresentados em anexo ao peticionamento. Produtos de risco 2 devem apresentar resultados do estudo de estabilidade acelerado na solicitação do registro (3).

A Lei 6.360/76 definiu um prazo máximo de cinco anos para a renovação de registro de produtos junto a Anvisa, incluindo saneantes. A cada 5 anos este registro deveria ser renovado, mantendo-se o mesmo número de registro (1). A Lei 13097/15 alterou a validade do registro para um prazo de até 10 anos, dependendo da natureza do produto e risco sanitário advindos de seu uso (17). A RDC 42/2009 definiu que notificações de saneantes de risco 1 possuem validade de 5 anos, podendo ser renovadas sucessivamente, por igual período, desde que a ação seja efetuada antes do seu vencimento (16).

Embalagem e rotulagem. Embalagens são recipientes destinados ao acondicionamento e proteção do produto contido. Para evitar mudanças no efeito do produto saneante ou prejuízo à saúde, as embalagens elaboradas ou revestidas por dentro com componentes que possam reagir com o produto devem passar por aprovação do Ministério da Saúde (1). De acordo com a RDC 47/2013, que trata das boas práticas de fabricação para produtos saneantes, os processos pelo qual o produto a granel passa até se tornar produto acabado faz parte do conceito de embalagem (18).

De acordo com a RDC 59/2010, as embalagens de produtos saneantes devem ser constituídas por materiais que não reajam com o produto, não provoquem alterações de cor ou transfiram odor, protejam o produto de contaminações externas e o acondicionem de forma eficaz. Devem ser vedadas de forma a previnir vazamentos e acidentes e não transmitir informações falsas. Estas não devem ter sido utilizadas previamente para acondicionamento de outros produtos (3).

O rótulo de um produto pode ser definido como uma identificação impressa, gravada por litografia, palavras pintadas, aplicadas ou gravadas em recipientes ou protetores de embalagem. A rotulagem de produtos saneantes não deve trazer qualquer sinal que possa dar origem a interpretações falsas, sendo que informações quanto à origem, procedência, natureza, qualidade, composição, características e finalidade do produto não devem dar margem a interpretações errôneas ou duvidosas (1).

A RDC 59/2010 determinou dizeres mínimos que devem constar na rotulagem, quando a superfície da embalagem não permitir todas as informações. Deve constar nome do produto, princípio ativo, lote, data de validade e a frase: "Antes de usar leia as instruções do prospecto explicativo". Demais informações devem constar no prospecto (3).

Saneantes desinfestantes. A RDC 326/2005 definia alguns critérios para embalagens de produtos desinfestantes. Apresentava, em um de seus anexos, o conteúdo máximo de produtos de venda livre que cada embalagem poderia apresentar. Embalagens de inseticidas deveriam ser de material resistente, de difícil ruptura e compatível com o produto, dificultando acidentes (19). Com a publicação da RDC 34/2010, estas regras passaram a ser válidas para todos os saneantes desinfestantes. Por exemplo, o conteúdo máximo de produtos em forma de gel por embalagem foi reduzido de $50 \mathrm{~g}$ para $20 \mathrm{~g}$. Estas duas Resoluções frisam a importância da utilização de dispositivos de segurança para direcionar o jato em embalagens de líquidos premidos (20).

A RDC 326/2005 determinava que os rótulos de desinfetantes de venda restrita deveriam conter os dizeres: «Venda restrita para entidades especializadas». Inseticidas e repelentes deveriam trazer as seguintes frases de advertência: «ATENÇÃO - CUIDADO», enquanto rodenticidas deveriam conter as palavras «CUIDADO - VENENO» acompanhado do desenho de uma caveira. Estes deveriam também conter no painel principal do rótulo a frase: «ANTES DE USAR LEIA AS INSTRUÇÕES DO RÓTULO». No no caso de produtos de venda restrita, os dizeres: «VENDA RESTRITA A INSTITUIÇÕES OU EMPRESAS ESPECIALIZADAS» deveriam ser utilizados (19).

A RDC 34/2010 revogou a RDC 326/2005, proibindo utilização de dizeres que possam confundir o consumidor sobre a finalidade, composição e eficácia do produto. Produtos que necessitem da utilização de Equipamentos de Proteção Individual (EPI) devem apresentar esta informação esclarecida no rótulo. Informações como o modo de uso e as pragas para o qual o produto é destinado devem estar especificadas. As frases de advertência continuaram obrigatórias, acrescentando a frase "PROIBIDA VENDA LIVRE" para produtos de venda restrita.

Assim como a Resolução anterior, o rótulo deve conter informações sobre o produto, tais como nome comercial, finalidade do produto, conteúdo, modo de aplicação, eficácia, atitudes a serem tomadas em caso de contato acidental ou intoxicações e outras informações específicas. O rótulo deve alertar sobre a importância de 
manter o produto fora do alcance de crianças e não aplicar sobre alimentos (20).

Detergentes e produtos de higienização e limpeza. A Resolução Normativa $n^{0} 1 / 78$ do Ministério da Saúde determinava, em um de seus anexos, as frases de advertência que produtos detergentes e produtos de higienização e limpeza deveriam conter, obrigatoriamente, em seus rótulos, embalagens, ou folhetos explicativos. Dentre as principais recomendações, ressaltava-se a importância de manter fora do alcance de crianças, não provocar vômito no caso de ingestão, lavar os olhos com água em abundância, no caso de contato e consultar um médico (21). De acordo com RDC 13/2007, que revogou a Resolução $n^{0} 1 / 78$, as embalagens dos produtos de limpeza deveriam ser resistentes para manter as características do produto estáveis e evitar rupturas e durante o transporte, guarda ou manuseio. Embalagens que lembrassem brinquedos deveriam ter sua segurança reforçada para evitar uma possível ingestão por crianças. Produtos em aerosol não deveriam ter suas embalagens perfuradas (22).

A RDC 13/2007 também definia regras para rótulos de produtos de limpeza e produtos destinados à conservação de superfícies e objetos. Estes deveriam conter informações verídicas e suficientes para o uso e características essenciais, podendo ressaltar benefícios, em casos justificados. Os rótulos deveriam conter o nome comercial, número de lote, a finalidade, instruções e precauções do uso do produto, o seu conteúdo líquido, os componentes ativos, a identificação da empresa, e, quando verificada, a incompatibilidade com outros materiais. Também deveriam conter frases de advertência, com o objetivo de evitar ou sanar acidentes, tais como: "Mantenha fora do alcance de crianças"; "Leia atentamente o rótulo antes de usar o produto"; "Em caso de contato com os olhos, lave imediatamente com água em abundância"; "Em caso de contato com a pele, lave imediatamente com água em abundância" e "Em caso de ingestão, não provoque vômito e consulte imediatamente o Centro de Intoxicações ou o médico levando o rótulo do produto". Frases específicas também deveriam ser utilizadas para categorias distintas. Produtos de uso profissional deveriam trazer a frase "Restrito ao uso profissional". Todas estas informações obrigatórias deveriam estar escritas de forma clara e legível em partes não removíveis do produto (22). Esta Resolução foi revogada pela RDC $40 / 2008$, que manteve as orientações quanto às informações relativas ao rótulo e embalagem (23).
Produtos biológicos de uso domissanitário. A RDC 117/2001, enquanto em vigor, estabelecia que as embalagens de produtos biológicos de uso domissanitário deveriam ser resistentes e de materiais compatíveis com o produto, diminuindo ao máximo o contato com o utilizador. A data de fabricação, a validade e o número do lote deveriam constar diretamente na embalagem, de forma indelével (24).

Quanto à rotulagem, a mesma Resolução estabelecia que produtos biológicos de uso domissanitário deveriam apresentar no painel principal de seus rótulos os seguintes dizeres: "CUIDADO! PERIGOSO SE INGERIDO, CONTÉM MICRORGANISMOS VIVOS” e "ANTES DE USAR LEIA COM ATENÇÃO AS INSTRUÇÕES DO RÓTULO”. Produtos de venda restrita a empresas especializadas deveriam trazer a frase: "PROIBIDA A VENDA DIRETA AO PÚBLICO”. Além disso, as seguintes informações deveriam constar na face principal do rótulo: nome comercial e conteúdo do produto, logotipo da empresa, e informações sobre os possíveis riscos associados a cada tipo de produto. Informações sobre a forma de uso, composição, restrições do uso, número de registro junto ao Ministério da Saúde, dados da empresa fabricante, país de origem e o número para contato com o Centro de Intoxicações poderiam figurar tanto no painel principal quanto no secundário (24).

A RDC 179/2006 revogou a RDC 117/2001, alterando as informações obrigatórias do rótulo de produtos biológicos de uso domissanitário. No painel principal deveriam constar as seguintes informações sobre o produto saneante: denominação, nome, marca e conteúdo. Os dizeres "CUIDADO! PERIGOSO SE INGERIDO, CONTÉM MICRORGANISMOS VIVOS", "ANTES DE USAR LEIA AS INSTRUÇÕES DO RÓTULO" e, em caso de venda restrita a empresas especializadas, "PROIBIDA A VENDA DIRETA AO PÚBLICO" continuariam obrigatórios. O número de registro passou a ser de responsabilidade da autoridade sanitária competente. Foram acrescentadas medidas de segurança, como a indicação do uso de luvas e informações sobre a empresa detentora do registro, que poderiam constar tanto no painel principal, quanto no secundário. Em relação à embalagem, mantinha as mesmas exigências da anterior (25). Esta Resolução foi revogada pela RDC 82/2016, que atualmente está em vigor. As orientações quanto a embalagem e rotulagem foram mantidas (26).

Saneantes com ação antimicrobiana. A Portaria 15/1988 do Ministério da Saúde não trazia nenhuma especificação a respeito da embalagem de saneantes com 
ação antimicrobiana (27). Esta foi revogada pela RDC 14/2007, que atualmente está em vigor, e determinou que estes produtos devem ser acondicionados em embalagens resistentes, que previnam acidentes e mantenham as características originais do produtos e que não sejam fabricadas com vidro (28).

Enquanto a Portaria estava em vigor, esta determinava que as seguintes informações deveriam constar nos rótulos: nome, classificação e restrições quanto ao uso do produto, modo e diluição de uso, tempo de contato, cuidados a serem tomados para a conservação, princípios ativos, lote, número de registro, data de fabricação, dados da empresa fabricante e a frase "ANTES DE USAR LEIA AS INSTRUÇÕES DO RÓTULO” (27). A RDC 14/2007, que revogou a Portaria, manteve estas informações como exigências para os rótulos, acrescidas das limitações quanto ao uso e possível menção do nome do responsável técnico da empresa fabricante. Frases específicas para cada classe de risco também devem constar no rótulo de saneantes antimicrobianos (28).

\section{Regularização e divulgação de informações}

A regularização do registro e notificação de produtos saneantes é imprescindível para a garantia mínima da qualidade dos produtos comercializados. As empresas que desejam registrar ou notificar novos produtos junto à Anvisa encontram nas legislações vigentes informações que podem auxiliá-las nestes processos, assim como uma forma mais simplificada, via formulários eletrônicos, para exercê-los.

A utilização de rótulos em embalagens de produtos saneantes facilita $\mathrm{o}$ acesso rápido a informações pertinentes ao consumidor, tais como: o modo correto de aplicar, a utilidade real do produto, a quem recorrer em caso de intoxicações e quais procedimentos adotar no caso de acidentes. A observação das informações obrigatórias constantes nos rótulos é importante para diferenciar produtos corretamente notificados ou registrados junto à Vigilância Sanitária de produtos falsos (2). As Resoluções atualmente em vigor apresentam normas cada vez mais específicas e voltadas para a segurança do usuário.

Devido aos riscos de intoxicações e acidentes que podem ocorrer durante a utilização de saneantes, a Anvisa determina que as embalagens destes produtos sejam feitas de materiais resistentes, que não reajam quimicamente com os produtos contidos e que facilitem a aplicação, prevenindo acidentes (3). Além de visar embalagens seguras à utilização por adultos, outro ponto importante, tratado pelas Resoluções, é o uso de formatos menos atrativos e dispositivos de segurança que evitem o contato acidental por crianças. Informações críticas como data de fabricação, validade e número do lote do produto devem estar demarcadas na embalagem para que possam sempre ser consultadas a qualquer momento $(20,23,25)$.

Apesar da evolução das legislações, ainda existem pontos que devem ser melhorados. Os atendentes dos Centros de Controle de Intoxicação devem receber treinamento para registrar todos os dados que podem ser úteis para futuras consultas. Dentre os dados registrados devem estar: identificação do agente intoxicante, como nome e marca do produto, idade e sexo do paciente e os fatos ocorridos após a prestação do atendimento, tais como cura, morte e sequelas decorrentes da intoxicação. Muitas vezes alguns dados são ignorados, o que dificulta a formação de uma base de dados confiável (9). Grande parte das intoxicações acidentais ocorrem com crianças, $o$ que indica a necessidade de programas educacionais que promovam a correta forma de armazenar saneantes (29).

O contato com a população deve ser aprimorado, para transmitir, de forma cada vez mais simples, informações sobre os riscos advindos do uso de saneantes. Boa parte dos consumidores de produtos saneantes não possuem acesso a informações contidas em sítios eletrônicos, sendo que a utilização de outros canais de comunicação, tais como televisivo e panfletos informativos, é crucial para reduzir cada vez mais os riscos de intoxicações e acidentes.

Os consumidores devem ser constantemente alertados sobre o risco de utilizar produtos saneantes clandestinos, pois apesar de preços baixos e atrativos, não apresentam qualquer vantagem sobre os produtos originais, cuja eficácia e segurança foi comprovada pela realização de testes (2). A Anvisa criou folhetos explicativos, demonstrando as principais diferenças, mas estes ainda devem ser melhor divulgados para alcançar o maior número de pessoas possível.

A atuação dos profissionais de saúde é imprescindível para a ampla divulgação de informações que podem prevenir acidentes, reduzir o número de intoxicações e manter o consumidor informado sobre as verdadeiras finalidades as quais cada produto deve ser utilizado.

\section{CONCLUSÃO}

A Anvisa vem cumprindo seu objetivo, de tornar cada vez mais seguro o desenvolvimento de atividades relacio- 
nadas a saneantes por empresas autorizadas. Em geral, as legislações em vigor trazem informações detalhadas sobre os procedimentos que devem ser adotados, conceitos esclarecidos, visando sempre a qualidade do produto, a segurança dos trabalhadores, a redução de potenciais eventos adversos e a preservação do meio ambiente. A população deve receber informações claras e de fácil entendimento para que se conscientizem dos riscos e benefícios advindos da utilização de produtos saneantes, assim como da importância de procurar produtos de qualidade.
A Anvisa, em conjunto com as Vigilâncias Sanitárias dos Estados e Municípios, atua na fiscalização de empresas licenciadas a produzir saneantes. A frequência destas fiscalizações poderia aumentar para garantir que os produtos que chegam ao mercado estejam apropriados para uso e cumpram os requisitos técnicos de segurança e qualidade. Todas as empresas que se comprometem a fabricar saneantes devem se ater ao bem-estar dos consumidores e a Vigilância Sanitária deve atuar para que esta meta se torne cada vez mais real.

\section{REFERÊNCIAS}

1. BRASIL. Ministério da Saúde. Lei ${ }^{\circ} 6.360$, de 23 de setembro de 1976. Dispõe sobre a Vigilância Sanitária a que ficam sujeitos os Medicamentos, as Drogas, os Insumos Farmacêuticos e Correlatos, Cosméticos, Saneantes e Outros Produtos, e dá outras Providências. Diário Oficial da União de 24 de setembro de 1976, Seção 1. p. 12647.

2. BRASIL. Agência Nacional de Vigilância Sanitária. Orientações para os consumidores de saneantes. [Acesso em 28 de maio de 2016]. Disponível em: http://www.anvisa.gov.br/saneantes/cartilha_saneantes.pdf

3. BRASIL. Agência Nacional de Vigilância Sanitária. Resolução RDC n ${ }^{\circ}$ 59, de 22 de dezembro de 2010. Dispõe sobre os procedimentos e requisitos técnicos para a notificação e o registro de produtos saneantes e dá outras providências. Diário Oficial da União, no 244 de 22 de dezembro de 2010, Seção 1. p. 80-82.

4. BRASIL. Agência Nacional de Vigilância Sanitária. Resolução RDC n ${ }^{\circ} 14$, de 28 de fevereiro de 2007. Aprova Regulamento Técnico para Produtos com Ação Antimicrobiana, harmonizado no âmbito do Mercosul, e dá outras providências. Diário Oficial da União, no 43 de 05 de março de 2007, Suplemento, Seção 1. p. 2-4.

5. Santos JAT, Seleghim MR, Marangoni SR, Gonçalves AM, Ballani TSL, Oliveira MLF. Gravidade de intoxicações por saneantes clandestinos. Texto contexto - enferm.. 2011; 20(spe): 247-254. DOI: 10.1590/S010407072011000500031 .

6. Fook SML, Azevedo EF, Costa MM, Feitosa ILF, Bragagnoli G, Mariz SR. Avaliação das intoxicações por domissanitários em uma cidade do Nordeste do Brasil. Cad. Saúde Pública. 2013; 29(5): 1041-1045. DOI: 10.1590/ S0102-311X2013000900021.

7. Corrêa LML. Saneantes domissanitários e saúde: Um estudo sobre a exposição de empregadas domésticas. [Tese]. Rio de Janeiro: Universidade Federal do Rio de Janeiro. 2005. [Acesso em 28 de maio de 2016]. Disponível em: http://www.posgraduacao.iesc.ufrj.br/media/ tese/1370441571.pdf

8. Silva AAR, Passos RS, Simeoni LA, Neves FAR, Carvalho $\mathrm{E}$. Use of sanitizing products: safety practices and risk situations. J. Pediatr. 2014; 90(2): 149-154. DOI: 10.1016/j.jped.2013.08.011.

9. Presgrave RF, Camacho LAB, Villas Boas MHS. Análise dos dados dos Centros de Controle de Intoxicação do Rio de Janeiro, Brasil, como subsídio às ações de saúde pública. Cad. Saúde Pública. 2009; 25(2): 401-408. DOI: 10.1590/S0102-311X2009000200019.

10. BRASIL. Ministério da Saúde. Lei n ${ }^{\circ} 9.782$, de 26 de janeiro de 1999. Define o Sistema Nacional de Vigilância Sanitária, cria a Agência Nacional de Vigilância Sanitária, e dá outras providências.Diário Oficial da União ${ }^{\circ}$ 18 de 27 de janeiro de 1999, Seção 1. p. 1-6.

11. BRASIL. Agência Nacional de Vigilância Sanitária. Resolução RDC n ${ }^{\circ} 16$, de 01 de abril de 2014. Dispõe sobre os Critérios para Peticionamento de Autorização de Funcionamento (AFE) e Autorização Especial (AE) de Empresas. Diário Oficial da União, ${ }^{\circ} 63$ de 02 de Abril de 2014, Seção 1. p. 58-60.

12. CRQ. Conselho Regional de Química. Guia para empresas de saneantes. [Acesso em 28 de maio de 2016]. Disponível em: http://crq4.org.br/sms/files/file/Guia_de_Saneantes5.pdf.

13. BRASIL. Secretaria de Vigilância Sanitária do Ministério da Saúde. Portaria no 57, de 11 de julho de 1995. Dispõe sobre o registro de produtos saneantes domissanitários e afins, de uso doméstico, institucional e profissional, levando-se em conta a avaliação e o gerenciamento do risco e dá outras providências. Diário Oficial da União, no 132 de 12 de julho de 1995, Seção 1. p. 10016-10020.

14. BRASIL. Agência Nacional de Vigilância Sanitária. Resolução 336, de 22 de julho de 1999. Dispõe sobre o registro de produtos saneantes domissanitários e afins, de uso domiciliar, institucional e profissional, levando-se em conta a avaliação e o gerenciamento do riscoe dá outras providências. Diário Oficial da União, no 140 de 23 de julho de 1999, Seção 1. p. 40-43.

15. BRASIL. Agência Nacional de Vigilância Sanitária. Resolução RDC $n^{\circ} 184$, de 22 de outubro de 2001. Dispõe sobre o registro de produtos saneantes domissanitários e afins, de uso domiciliar, institucional e profissional, alterando a Resolução 336, de 30 de julho de 1999. e dá 
outras providências. Diário Oficial da União, no 203 de 23 de outubro de 2001, Seção 1. p. 42-46.

16. BRASIL. Agência Nacional de Vigilância Sanitária. Resolução RDC n ${ }^{\circ} 42$, de 13 de agosto de 2009. Dispõe sobre procedimento, totalmente eletrônico, para a notificação à Agência Nacional de Vigilância Sanitária - ANVISA, de Produtos Saneantes de Risco I, em substituição ao disposto na Resolução RDC $\mathrm{n}^{\circ} 184$, de 22 de outubro de 2001 e dá outras providências. Diário Oficial da União, $\mathrm{n}^{\circ} 155$ de 14 de agosto de 2009, Seção 1. p. 82-83.

17. BRASIL. Agência Nacional de Vigilância Sanitária. Lei $\mathrm{n}^{\circ}$ 13097, de 29 de dezembro de 2015. Altera a Lei $\mathrm{n}^{\circ}$ 6.360 , de 23 de setembro de 1976, que "dispõe sobre a Vigilância Sanitária a que ficam sujeitos os Medicamentos, as Drogas, os Insumos Farmacêuticos e Correlatos, Cosméticos, Saneantes e Outros Produtos, e dá outras Providências, para estabelecer medidas que inibam erros de dispensação e de administração e uso equivocado de medicamentos, drogas e produtos correlatos.Diário Oficial da União, n 249 de 30 de dezembro de 2015, Seção 1. p. 2 .

18. BRASIL. Agência Nacional de Vigilância Sanitária. Resolução RDC n ${ }^{\circ} 47$, de 25 de outubro de 2013. Aprova o Regulamento Técnico de Boas Práticas de Fabricação para Produtos Saneantes, e dá outras providências. Diário Oficial da União, no 209 de 28 de outubro de 2013, Seção 1. p. 58-63.

19. BRASIL. Agência Nacional de Vigilância Sanitária. Resolução RDC no 326, de 09 de novembro de 2005. Aprova o Regulamento técnico para produtos desinfestantes domissanitários harmonizado no âmbito do Mercosul através da Resolução GMC no 49/99. Diário Oficial da União, no 218 de 14 de novembro de 2005, Seção 1. p. $1-5$.

20. BRASIL. Agência Nacional de Vigilância Sanitária. Resolução RDC n ${ }^{\circ} 34$, de 16 de agosto de 2010. Dispõe sobre o Regulamento Técnico para produtos saneantes desinfestantes. Diário Oficial da União, nº 158 de 18 de agosto de 2010, Seção 1. p. 42-46.

21. BRASIL. Ministério da Saúde. Conselho Nacional de Saúde. Câmara Técnica de Medicamentos. Resolução Normativa $n^{\circ} 1$, de 30 de agosto de 1978. Dispõe sobre o estabelecimento de uma sistemática da experimentação terapêutica, bem como de todos os itens que devem ser abrangidos nas suas diversas etapas. Diário Oficial da União, no 198 de 17 de outubro de 1978, Seção 1. p. 16746.

22. BRASIL. Agência Nacional de Vigilância Sanitária. Resolução RDC n 13, de 28 de fevereiro de 2007. Apro- va Regulamento Técnico para produtos de limpeza e afins, harmonizado no âmbito do Mercosul, e dá outras providências. Diário Oficial da União, no 43 de 05 de março de 2007, Seção 1. p. 1-2.

23. BRASIL. Agência Nacional de Vigilância Sanitária. Resolução RDC $n^{\circ} 40$, de 05 de junho de 2008. Aprova o Regulamento Técnico para produtos de limpeza e afins harmonizado no âmbito do Mercosul através da Resolução GMC no 47/07. Diário Oficial da União, n 107 de 06 de junho de 2008, Seção 1. p. 57-58.

24. BRASIL. Agência Nacional de Vigilância Sanitária. Resolução RDC no 117, de 11 de junho de 2001. Republicar a Norma Geral para produtos biológicos de uso domissanitário, elaborada pela Comissão Técnica de Assessoramento na Área de Saneantes Domissanitários CTAS, aprovada pela Portaria $\mathrm{n}^{\circ} 719$, de 10 de setembro de 1998, Republicado no DOU n ${ }^{\circ}$ de 17 de setembro de 1998, e demais alterações pertinentes, estendendo a destinação para uso domiciliar. Diário Oficial da União, $n^{\circ}$ 114 de 13 de junho de 2001, Seção 1. p. 61-62.

25. BRASIL. Agência Nacional de Vigilância Sanitária. Resolução RDC no 179, de 03 de outubro de 2006. Aprovar o Regulamento Técnico para produtos saneantes à base de bactérias harmonizado no âmbito do Mercosul através da Resolução GMC n 25/06. Diário Oficial da União, n ${ }^{\circ}$ 191 de 04 de outubro de 2006, Seção 1. p. 66-67.

26. BRASIL. Agência Nacional de Vigilância Sanitária. Resolução RDC no 82, de 03 de junho de 2016. Aprova o Regulamento Técnico para produtos saneantes à base de bactérias e dá outras providências. Diário Oficial da União, nº 106 de 02 de junho de 2016, Seção 1. p. 41-42.

27. BRASIL. Ministério da Saúde, Secretaria Nacional de Vigilância Sanitária. Portaria $n^{\circ} 15$, de 23 de agosto de 1988. Determina que o registro de produtos saneantes domissanitários com finalidade antimicrobiana seja procedido de acordo com as normas regulamentares. Diário Oficial da União, de 05 de setembro de 1988, Seção 1. p. 17041-3.

28. BRASIL. Agência Nacional de Vigilância Sanitária. Resolução RDC n 14, de 28 de fevereiro de 2007. Aprova Regulamento Técnico para produtos com ação antimicrobiana, harmonizado no âmbito do Mercosul, e dá outras providências. Diário Oficial da União, n ${ }^{\circ} 43$ de 05 de março de 2007, Seção 1. p. 2-4.

29. Presgrave RF, Camacho LAB, Villas Boas MHS. A profile of unintentional poisoning caused by household cleaning products, disinfectants and pesticides. Cad. Saúde Pública. 2008; 24(12): 2901-2908. DOI: 10.1590/ S0102-311X2008001200019. 